\title{
Performance and Economic Analysis of Multi-Rotor Wind Turbine
}

\author{
Navjot Singh Sandhu*1, Saurabh Chanana² \\ ${ }^{*}$ School of Renewable Energy and Efficiency, National Institute of Technology, \\ Kurukshetra, Haryana - 136119, India, E-mail: navjotsingh.sandhu1990@gmail.com \\ 2Department of Electrical Engineering, National Institute of Technology, \\ Kurukshetra, Haryana - 136119, India, E-mail: schanana75@gmail.com
}

\begin{abstract}
Power output of a wind turbine depends upon its rotor size and at present wind turbines with large rotor diameter $(>175 \mathrm{~m})$ are available in the market. However major problems associated with such large size conventional turbines are their cost \& noise pollution. Due to these reason researchers have diverted their attention towards lower sized equivalent multi-rotor wind turbines. These turbines are found to be cheaper and good performers. Keeping it in view, in this paper an effort has been made to compare the energy yield and economics of two types of wind turbines i.e. single rotor \& multi rotor wind turbine. Power, energy and cost models as proposed are used to find the energy yield and economics of multi-rotor turbines. Simulation results as presented in this research paper justify the suitability of multi-rotor wind turbine in place of single rotor configuration. Such turbines deliver more energy yield with low installation cost in contrast to single rotor turbines.
\end{abstract}

Keywords: Multi-rotor wind turbine, Power curve model, Wind energy, Wind turbine, Wind turbine cost.

\section{INTRODUCTION}

As far as growth of wind energy is concerned, presently it has acquired the major share among all renewable energy resources [1-3]. At the end of 2017, worldwide power generation using wind as resource is 539.291GW. Wind turbine is used to extract the power associated with moving wind. Power developed by wind turbine is dependent upon its rotor swept area $(A)$, coefficient of performance $\left(C_{p}\right) \&$ wind speed $(v)$. In order to increase the power production, manufacturers are designing the conventional wind turbine with large size rotors [4]. However major problems [5-7] associated with large sized rotor (such as its cost, noise etc.) are restricting their popularity for wind power production. Therefore people have diverted their attention towards multirotor wind turbines with small size rotors. Multirotor wind turbines (i.e. two or more rotor on a single support) are an old concept [9] and in 1978 dick [10] observed the performance of a downstream turbine rotor just behind the upstream turbine rotor. Later on Kotb et al. [11] 
investigated the performance of staggered horizontal axis rotors and predicted the power loss due to upstream rotor. 15\% power loss was predicted for a 0.26 overlap area ratio. No et al. [12] developed a FORTRAN and Matlab/Simulink software to predict the performance of a dual rotor wind turbine generating system. In order to reduce power block, size of upstream rotor was considered small as compared to downstream rotor. Yap et al. [13] discussed the electricity generation due to dual rotor wind turbine located near the exhausting gases in a plant and its effects on the performance of cooling tower. Habash et al. [14] investigated a dual rotor scaled down turbine structure and conclude that a dual rotor turbine may produce up to $60 \%$ more power than a single rotor turbine. Some of the researchers [15-16] made a comparison of single rotor \& dual rotor turbines under transient disturbances. It was observed that dynamic response of a dual rotor system is more stable. Jamieson et al. [8] made a cost comparison of $20 \mathrm{MW}$ conventional wind turbine with a $20 \mathrm{MW}$ multirotor turbine comprising of four rotors with each one of $5 \mathrm{MW}$. It was observed that four 5 MW rotors will cost about $80 \%-89 \%$ of a $20 \mathrm{MW}$ single rotor structure and there is a further scope to reduce its cost. It was suggested that there is a need to focus more attention to the research related to multi rotor turbines. Hunag et al. [17] also made a comparison of single rotor and multirotor wind turbines when used in a wind solar hybrid generation. It was found that at a low wind speeds, the multirotor wind turbine-solar hybrid generation performs better in contrast to single rotor wind turbine-solar hybrid generation. Jamieson et al. [18] also investigated the support structure consideration and presented one potential structure layout for a $20 \mathrm{MW}$ multirotor turbine.

After going through the relevant literature review it is observed that:

- Conventional wind turbines with larger rotor size can be replaced by some equivalent multi rotor wind turbine with small rotor size.

- More research is required to analyze the performance of multirotor wind turbine in terms of their suitability to replace the single rotor wind turbine.

Keeping in view the above observations, focus of the paper is to analyze the performance and cost of a multi rotor wind turbine which can be installed in place of a large single rotor wind turbine. Weibull distributions with different values of mean wind speeds have been considered to compare the performance of single-rotor wind turbine with that of multi-rotor configuration. In the present paper 'curve fit model' has been used to develop the power and energy model of a multirotor wind turbine. Further 'power and energy model' as developed is applicable to all of the three configurations as shown in figure 2. The manufacturer data has been used to find out the six coefficients of 'curve fit model'. Therefore simulation results as obtained for energy yield are exact replica of actual power output as if wind turbine has been installed. 
For the first time a new cost model has been proposed, which includes the details of various components of wind turbine. Detailed description has been given to justify the cost saving without any compromise on other parameters. Effect of the cost of gear box has been reflected, which gives a new dimension for the further related research. Further this model also includes the operating and maintenance costs.

Uniqueness of this paper is the development of new power, energy and cost models used for the detailed comparison of energy yield and cost of a multi-rotor wind turbine (with all possible configurations) with that of single rotor wind turbine, when such turbines are installed at different windy sites with different wind characteristics.

Simulated results as presented will attract the researchers to give a focus on the design of multi rotor wind turbine for maximum savings. Results as presented and discussed in section 5 proves the effectiveness of multirotor wind turbine in terms of more energy yield with low installation cost.

\section{POWER AND ENERGY MODELS OF SINGLE ROTOR WIND TURBINE}

Power output of a turbine as shown in figure 1 may be obtained using equation (1). Wind speed $(v)$ is considered at the hub height $(\mathrm{h})$ of wind turbine.

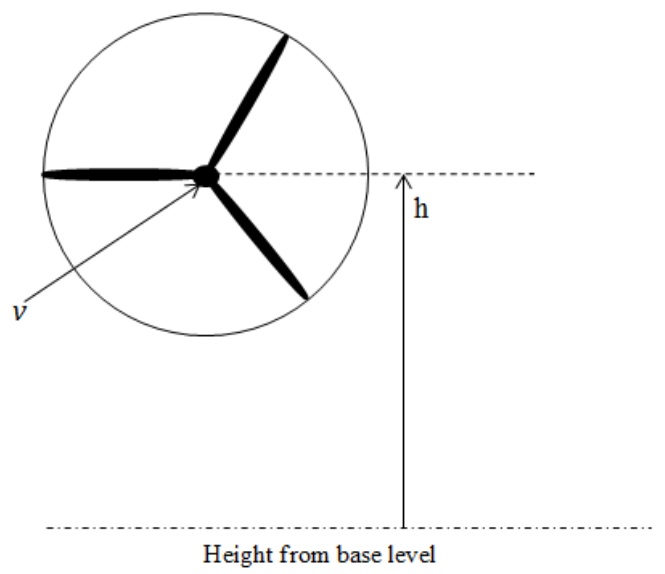

(a)

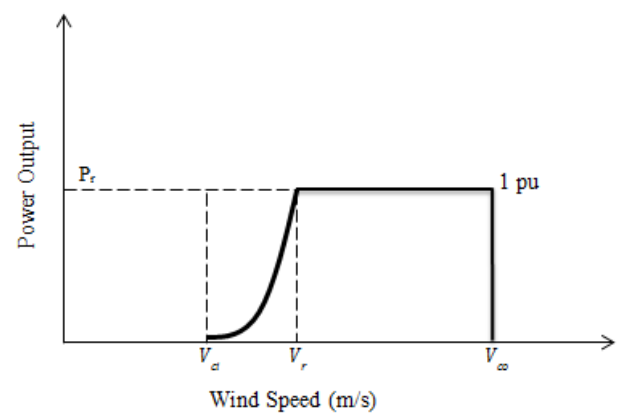

(b)

Figure 1. (a) Single-rotor wind turbine representation (b) Power output curve 


$$
P=\left\{\begin{array}{c}
0 v<v_{c i} \text { or } \quad v>v_{c o} \\
P_{v} \quad v_{c i} \leq v \leq v_{r} \\
P_{r} \quad v_{r} \leq v<v_{c o}
\end{array}\right\}
$$

Where;

$v_{\text {ci }}=$ Cut-in wind speed $(\mathrm{m} / \mathrm{s})$,

$v_{\text {co }}=$ Cut-out wind speed $(\mathrm{m} / \mathrm{s})$,

$v_{\mathrm{r}}=$ Rated wind speed $(\mathrm{m} / \mathrm{s})$,

$P(v)=$ Power output of wind turbine corresponding to any wind speed between cut-in to rated values,

$P_{r}=$ Rated output of wind turbine.

Power output from cut in to rated wind speed has been computed using the curve fit model using the manufacturer data. This comes out to be a sixth order polynomial expression in terms of wind speed (shown in table 1).

Two parameters Weibull Function as given by equation (2) are found to be best to fit the wind speed distribution over a period of time. However selection of shape parameter (k) and scale parameter (c) as used are significant to define the mean speed of wind at a specific site. Scale factor is usually taken 1.1 times the average or mean wind speed. $\mathrm{k}$ is the Weibull shape parameter. It specifies the shape of a Weibull distribution and takes on a value of between 1 and 3 . A small value for $k$ signifies very variable winds, while wind variations for most of the windy sites (with mean wind speed equal or greater than $5 \mathrm{~m} / \mathrm{s}$ ) are characterized by a larger $\mathrm{k}$. Wind variation decreases with an increase in the value of $\mathrm{k} . \mathrm{k}>3$ is an indication of regular and steady wind. For the value of $k=1$, the relative frequency distribution appears to be flat i.e. highly variable wind regime. For $\mathrm{k}=2$, distribution is called Rayleigh distribution.

$$
f(v)=\left(\frac{k}{c}\right)\left(\frac{v}{c}\right)^{k-1} e^{-\left(\frac{v}{c}\right)^{k}}
$$

Weibull distribution function as obtained using above equation and power curve model as defined by equation (1) may be used to estimate the annual energy yield (E) of the wind turbine as:

$$
E=\sum_{v_{c i}}^{v_{r}} P(v) * f_{I I}(v) * 8760+\sum_{v_{r}}^{v_{c o}} P_{r} * f_{I I I}(v) * 8760
$$

' $f_{I I}(v) \& f_{I I I}(v)$ 'are the speed frequencies for wind speed range $\left(v_{c i}\right.$ to $\left.v_{r}\right) \&$ $\left(v_{r}\right.$ to $v_{c o}$ ) respectively [figure $1(\mathrm{~b})$ ] and 8760 is the total number of hours in a year. 


\section{POWER AND ENERGY MODELS OF MULTI-ROTOR WIND TURBINE}

Equivalent multirotor representation as shown in figure 2 is used to develop the power and energy models. Height of tower in both types of turbines has been taken same as ' $h$ ' mts. Fixation of the rotors in case of multi-rotor wind turbine has been described in Appendix-A. Possible geometrical positions of the three rotors as considered are as below:

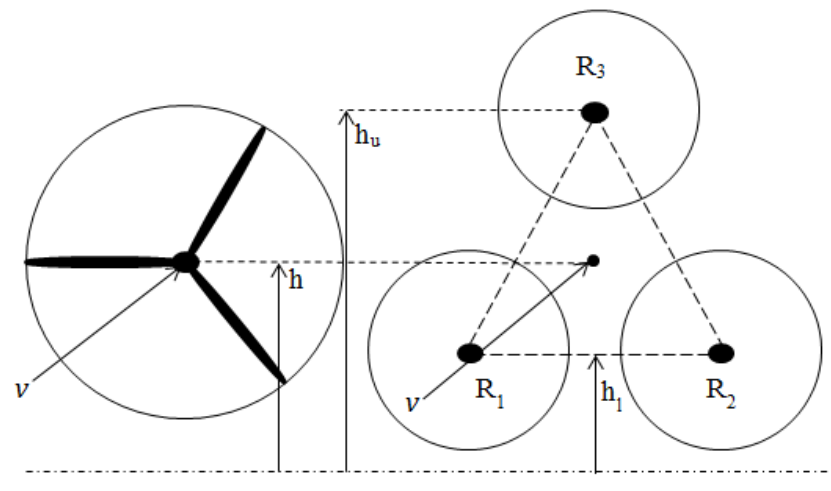

(a)

Heights from base level

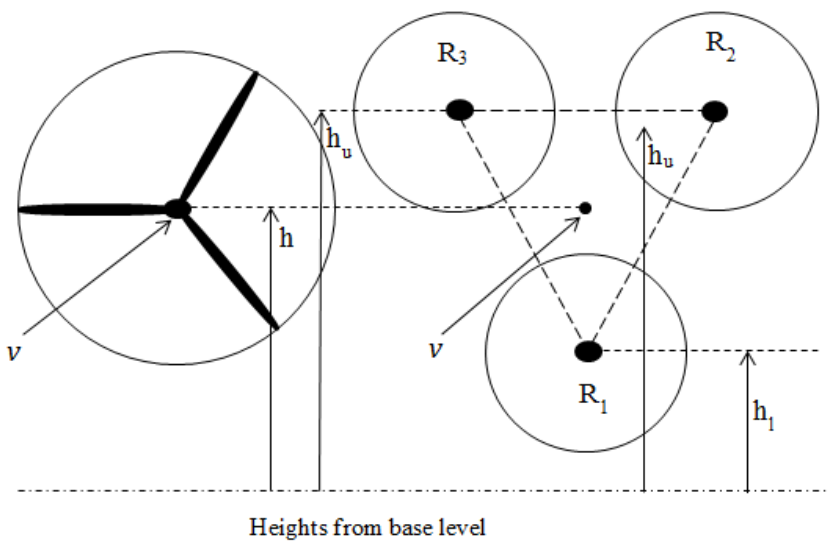

(b)

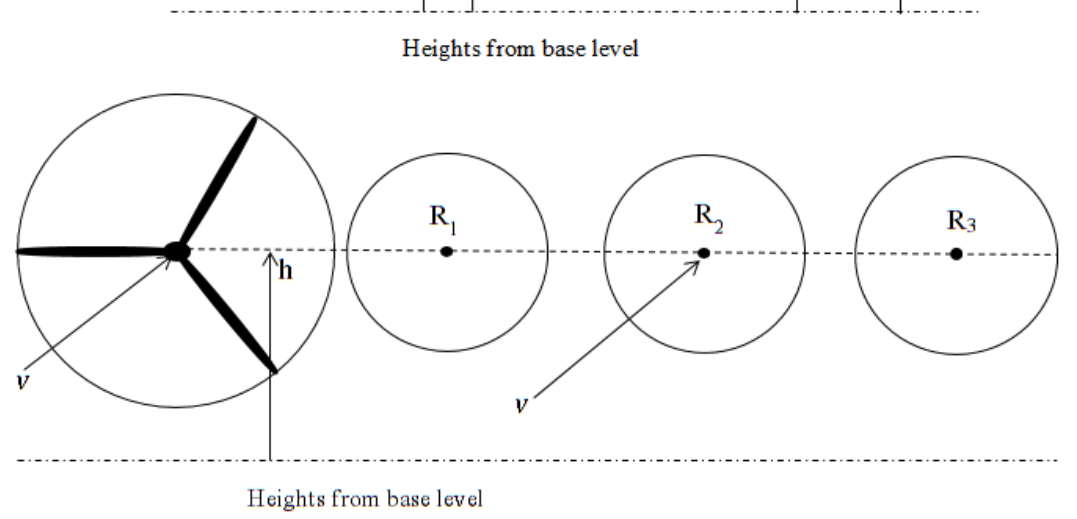

(c)

Figure 2. Multi rotor wind turbine (a) Rotors triangularly spaced with one at the top and other two at bottom, (b) Rotors triangularly spaced with one at bottom and other two at top, (c) All the three rotors aligned

Case-A: Rotors triangularly spaced with one at the top and other two at bottom, figure $2(\mathrm{a})$. 
Case-B: Rotors triangularly spaced with one at bottom and other two at top, figure 2(b).

Case-C: All the three rotors aligned, figure 2 (c).

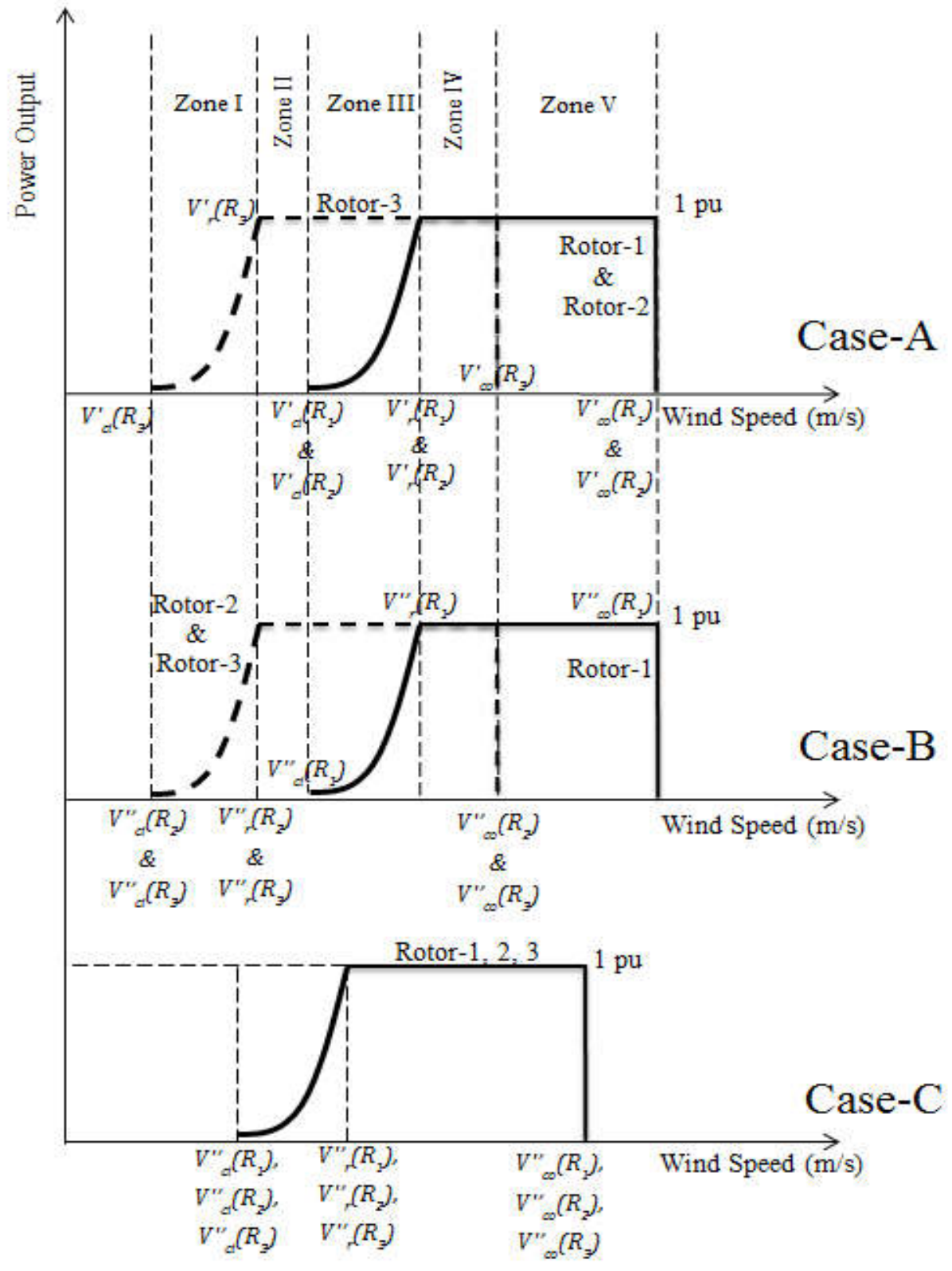

Figure 3. Power output curves

Separation between the adjacent rotors is $5 \%$ of rotor diameter [19]. Such separation is found to be sufficient to overcome the undesirable proximity effect of adjacent rotors. Operation of wind turbines in a closely spaced array is successfully demonstrated [20] with no negative impact of power performance. However cross wind separation of 2 to 5 times the rotor 
diameter [21] is required in a wind farm to reduce the wake effect or wind overlapping in the direction of wind flow.

Figure 3 shows the power output curves of multirotor wind turbines for respective cases. Displacement between the power curves as shown in figure $3(\mathrm{a}) \&(\mathrm{~b})$ is due to the different hub heights. Due to this reason, cut-in, rated and cut-out speed of the rotors will be different (Case-A \& Case-B). However power output curve for Case-C [figure 3(c)] appears to be identical (in terms of cut-in, rated \& cut-out speeds) as in case of single rotor wind turbine [figure 1(b)]. Effective values of cut-in, rated \& cut-out speeds of different rotors for respective cases are indicated as shown in figure 3.

Power outputs (РмA) for case-A \& (РМв) for case-B are defined as:

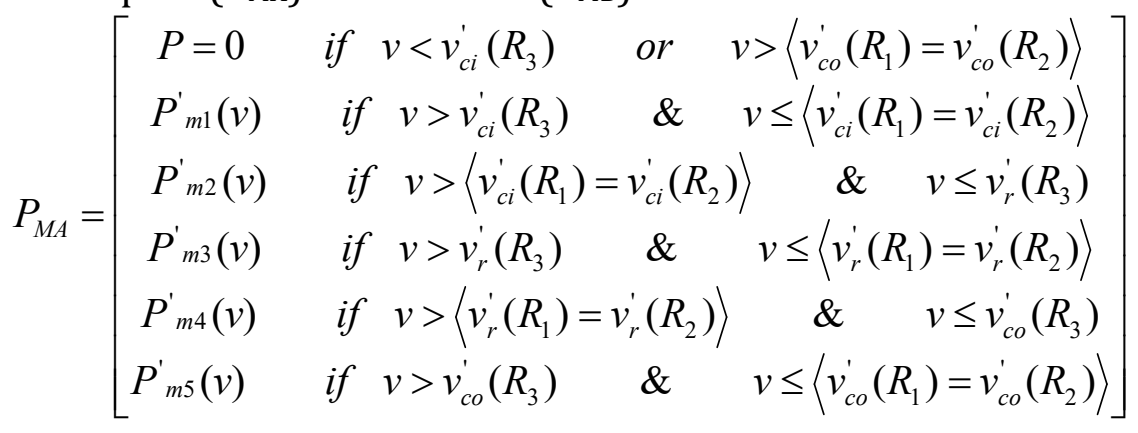

Where;

$\mathrm{P}^{\prime}{ }_{\mathrm{m} 1}=$ As per power curve model of rotor-3; when $v$ varies

$$
\text { from } v_{c i}^{\prime}\left(R_{3}\right) \text { to }\left\langle v_{c i}^{\prime}\left(R_{1}\right)=v_{c i}^{\prime}\left(R_{2}\right)\right\rangle
$$

$\mathrm{P}_{\mathrm{m} 2}^{\prime}=$ Sum of power as per power curve model of all rotors; when $v$

$$
\text { varies from }\left\langle v_{c i}^{\prime}\left(R_{1}\right)=v_{c i}^{\prime}\left(R_{2}\right)\right\rangle \text { to } v_{r}^{\prime}\left(R_{3}\right)
$$

$\mathrm{P}_{\mathrm{m} 3}=$ Rated power of rotor-3 + sum of power as per power curve model of rotor-1\&2; when $v$ varies from $v_{r}^{\prime}\left(R_{3}\right)$ to $\left\langle v_{r}^{\prime}\left(R_{1}\right)=v_{r}^{\prime}\left(R_{2}\right)\right\rangle$ $\mathrm{P}^{\prime}{ }_{\mathrm{m} 4}=$ Sum of rated power of all rotors; when $v$ varies from

$$
\left\langle v_{r}^{\prime}\left(R_{1}\right)=v_{r}^{\prime}\left(R_{2}\right)\right\rangle \text { to } v_{c o}^{\prime}\left(R_{3}\right)
$$

$\mathrm{P}_{\mathrm{m} 5}^{\prime}=$ Sum of rated power of rotors- $1 \& 2$; when $v$ varies from

$$
v_{c o}^{\prime}\left(R_{3}\right) t o\left\langle v_{c o}^{\prime}\left(R_{1}\right)=v_{c o}^{\prime}\left(R_{2}\right)\right\rangle
$$




$$
P_{M B}=\left[\begin{array}{ccccc}
P=0 & \text { if } v<\left(v_{c i}^{\prime \prime}\left(R_{3}\right)=v_{c i}^{\prime \prime}\left(R_{2}\right)\right) & \text { or } & v>\left\langle v_{c o}^{\prime \prime}\left(R_{1}\right)\right\rangle \\
P^{\prime \prime}{ }_{m 1}(v) & \text { if } v>\left(v_{c i}^{\prime \prime}\left(R_{3}\right)=v_{c i}^{\prime \prime}\left(R_{2}\right)\right) & \& & v \leq\left\langle v_{c i}^{\prime \prime}\left(R_{1}\right)\right\rangle \\
P^{\prime \prime}{ }_{m 2}(v) & \text { if } v>\left\langle v_{c i}^{\prime \prime}\left(R_{1}\right)\right\rangle & \& & v \leq\left(v_{r}^{\prime \prime}\left(R_{3}\right)=v_{r}^{\prime \prime}\left(R_{2}\right)\right) \\
P^{\prime \prime}{ }_{m 3}(v) & \text { if } v>\left(v_{r}^{\prime \prime}\left(R_{3}\right)=v_{r}^{\prime \prime}\left(R_{2}\right)\right) & \& & v \leq\left\langle v_{r}^{\prime \prime}\left(R_{1}\right)\right\rangle \\
P^{\prime \prime}{ }_{m 4}(v) & \text { if } & v>\left\langle v_{r}^{\prime \prime}\left(R_{1}\right)\right\rangle & \& & v \leq\left(v_{c o}^{\prime \prime}\left(R_{3}\right)=v_{c o}^{\prime \prime}\left(R_{2}\right)\right) \\
P^{\prime \prime}{ }_{m 5}(v) & \text { if } & v>\left(v_{c o}^{\prime \prime}\left(R_{3}\right)=v_{c o}^{\prime \prime}\left(R_{2}\right)\right) & \& & v \leq\left\langle v_{c o}^{\prime \prime}\left(R_{1}\right)\right\rangle
\end{array}\right]
$$

$\mathrm{P}^{\prime \prime}{ }_{\mathrm{m} 1}=$ Sum of power as per power curve model of rotor- $2 \& 3$; when $v$ varies

$$
\text { from }\left(v_{c i}^{\prime \prime}\left(R_{3}\right)=v_{c i}^{\prime \prime}\left(R_{2}\right)\right) \operatorname{to}\left\langle v_{c i}^{\prime \prime}\left(R_{1}\right)\right\rangle
$$

$\mathrm{P}_{\mathrm{m} 2}=$ Sum of power as per power curve model of all rotors; when $v$ varies

$$
\text { from }\left\langle v_{c i}^{\prime \prime}\left(R_{1}\right)\right\rangle \text { to }\left(v_{r}^{\prime \prime}\left(R_{3}\right)=v_{r}^{\prime \prime}\left(R_{2}\right)\right)
$$

$\mathrm{P}^{\prime \prime}{ }_{\mathrm{m} 3}=$ Sum of rated power of rotors- $2 \& 3+$ as per power curve model of rotor-1; when $v$ varies from $\left(v_{r}^{\prime \prime}\left(R_{3}\right)=v_{r}^{\prime \prime}\left(R_{2}\right)\right)$ to $\left\langle v_{r}^{\prime \prime}\left(R_{1}\right)\right\rangle$

$\mathrm{P}^{\prime \prime}{ }_{\mathrm{m} 4}=$ Sum of rated power of all rotors; when $v$ varies from

$$
\left\langle v_{r}^{\prime \prime}\left(R_{1}\right)\right\rangle \text { to }\left(v_{c o}^{\prime \prime}\left(R_{3}\right)=v_{c o}^{\prime \prime}\left(R_{2}\right)\right)
$$

$\mathrm{P}{ }_{\mathrm{m} 5}=$ Rated power of rotors-1; when $v$ varies from

$$
\left(v_{c o}^{\prime \prime}\left(R_{3}\right)=v_{c o}^{\prime \prime}\left(R_{2}\right)\right) t o\left\langle v_{c o}^{\prime \prime}\left(R_{1}\right)\right\rangle
$$

Power output for nonlinear portions of the curves (figure 3) has been computed with the 'curve fit model' using the manufacturer data. These expressions come out to be sixth order polynomial expressions in terms of wind speed (shown in table 1).

Annual energy yields ( $\left.\mathrm{E}_{\mathrm{MA}}\right)$ for case-A \& $\left(\mathrm{E}_{\mathrm{MB}}\right)$ for case-B may be obtained as: 


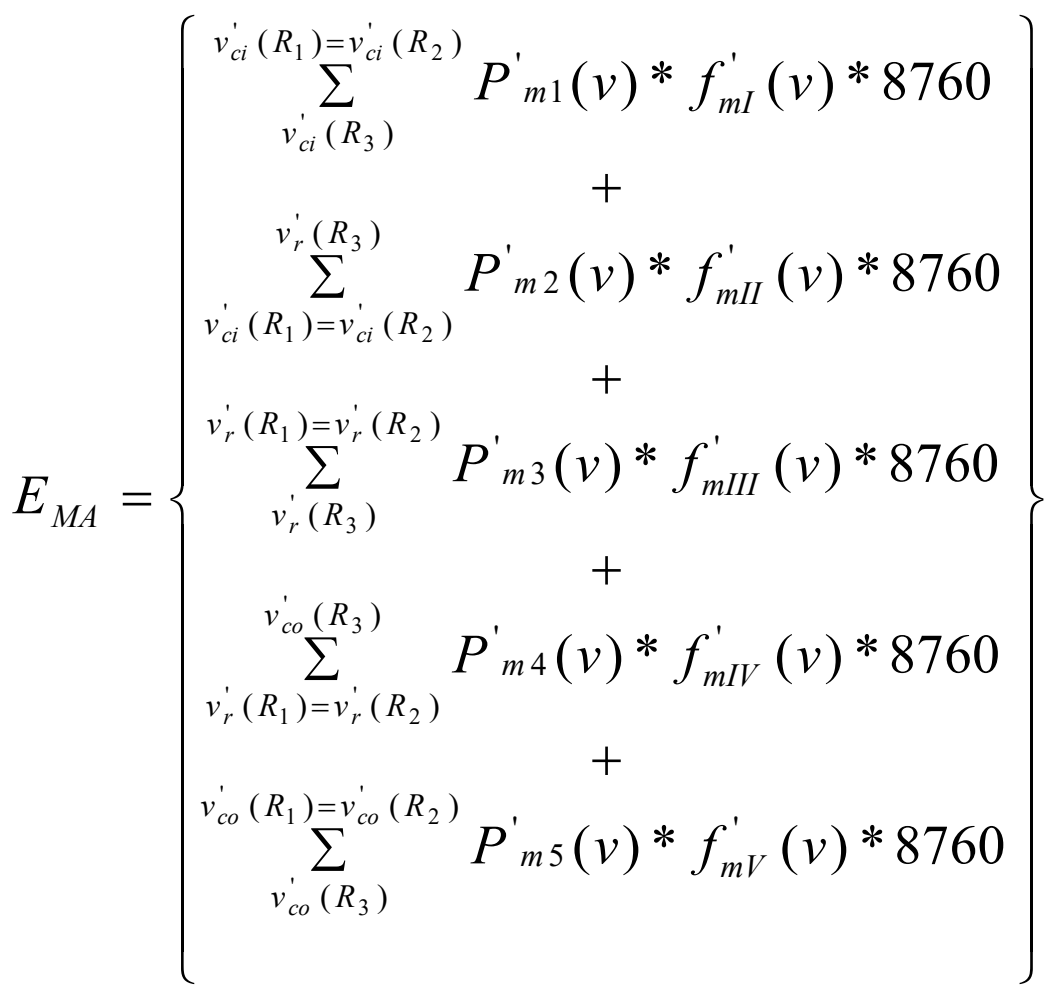

$f_{m I}^{\prime}(v), f_{m I I}^{\prime}(v), f_{m I I I}^{\prime}(v), f_{m I V}^{\prime}(v)$ and $f_{m V}^{\prime}(v)$ are the respective speed frequencies as per Weibull distribution for zones I, II, III, IV \& V (figure 3a).

$$
E_{M B}=\left\{\begin{array}{cc}
\sum_{c i}^{v_{c i}^{\prime \prime}\left(R_{1}\right)} P_{m 1}^{\prime \prime}(v) * f_{m I}^{\prime \prime}(v) * 8760 \\
v_{c i}^{\prime \prime}\left(R_{3}\right)=v_{c i}^{\prime \prime}\left(R_{2}\right) \\
v_{r}^{\prime \prime}\left(R_{3}\right)=v_{r}^{\prime \prime}\left(R_{2}\right) & P_{m 2}^{\prime \prime}(v) * f_{m I I}^{\prime \prime}(v) * 8760 \\
\sum_{c i}^{\prime \prime}\left(R_{1}\right) & + \\
\sum_{r}^{\prime \prime}\left(R_{3}\right)=v_{r}^{\prime \prime}\left(R_{2}\right) & P_{m 3}^{\prime \prime}(v) * f_{m I I I}^{\prime \prime}(v) * 8760 \\
v_{c o}^{\prime \prime}\left(R_{3}\right)=v_{c o}^{\prime \prime}\left(R_{2}\right) & P^{\prime \prime}{ }_{m 4}(v) * f_{m I V}^{\prime \prime}(v) * 8760 \\
\sum_{v_{r}^{\prime \prime}\left(R_{1}\right)}^{n} & + \\
\sum_{c c}^{\prime \prime}\left(R_{1}\right) & P_{m 5}^{\prime \prime}(v) * f_{m V}^{\prime \prime}(v) * 8760 \\
v_{c o}^{\prime \prime}\left(R_{3}\right)=v_{c o}^{\prime \prime}\left(R_{2}\right) &
\end{array}\right\}
$$


$f_{m I}^{\prime \prime}(v), f_{m I I}^{\prime \prime}(v), f_{m I I}^{\prime \prime}(v), f_{m I V}^{\prime \prime}(v)$ and $f_{m V}^{\prime \prime}(v)$ are the respective speed frequencies as per Weibull distribution for zones I, II, III, IV \& V (figure 3b).

Hub height of all the three rotors [figure 2(c)] is same as that of single rotor wind turbine. Power output curve [figure 3(c)] appears to be same as for single rotor wind turbine [figure 1(b)]. Therefore, power output and annual energy yield for case-c will be three times that in case of single rotor wind turbine. Equations (1) to (3) are used to compute power output and annual energy yield for case-C.

\section{COST MODEL}

Some of the points as listed below are used to develop the cost model of n-rotor wind turbine.

- Major components considered for the cost comparison are rotor blade, bearings, pitch control system, hub system, gearbox, tower and its foundation.

- Depending upon the type of gearbox used $[8,19]$, cost of gearbox will be ' $\mathrm{kg}$ ' times the cost of gearbox in single rotor wind turbine. Where $\mathrm{kg}$ is a constant and its maximum value cannot be more than one [19].

- Overall reduction of mass or weight [8] of nacelle and rotors $\left[\frac{1}{\sqrt{n}}\right.$ times the

single rotor wind turbine] will affect the cost of tower and its foundation accordingly.

- Tower cost will depend upon the weight of tower. For n-rotor wind turbine its weight is about seventy six percent [Appendix A] that in case of single rotor turbine.

- Foundation strength depends upon the weight and forces occurring on it. Major weight which is to be accounted for its design is due to tower, rotor and nacelle. Any change in the total weight will affect the cost of foundation accordingly and hence maximum possible saving may be taken as $\frac{1}{\sqrt{n}}$ times that in case of single rotor wind turbine.

- Cost of all other components (not mentioned above) may be assumed to be same for two types of wind turbines.

Following equations as developed [22-26] are used to evaluate the cost of major components of a wind turbine.

$$
\text { Blade Cost }=\frac{\left[\left(0.4019 * R^{3}-955.24\right)+\left(2.7445 * R^{2.5205}\right)\right]}{(1-0.28)}
$$

Where; $\mathrm{R}=$ Rotor radius

$$
\text { Hub Cost }=\left\{\left(0.954 * 0.1452 * R^{2.9158}\right)+5680.3\right\} * 4.25
$$




$$
\begin{gathered}
\text { Pitch System Cost }=2.28 *\left(0.2106 *(2 * R)^{2.6578}\right) \\
\text { Bearing System Cost }=2 *\left\{\left((2 * R) * \frac{8}{600}-0.033\right) *\left(0.0092 *(2 * R)^{2.5}\right)\right\} * 17.6 \\
\text { Foundation cost, } \mathrm{C}_{\mathrm{fs}}=16 \% \text { of total Project Cost } \\
\text { Tower cost, } \mathrm{C}_{\mathrm{ts}}=16.38 \% \text { of total Project Cost } \\
\text { Gear box cost, } \mathrm{C}_{\mathrm{gs}}=8.2624 \% \text { of total Project Cost }
\end{gathered}
$$

Cost saving in case of n-rotor wind turbine may be defined as:

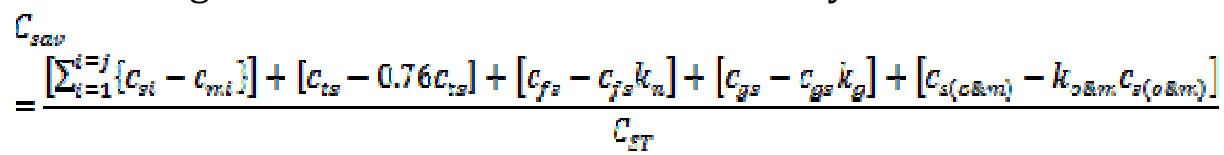

Where:

$C_{s a v}=$ per unit cost saving for multi-rotor wind turbine with 'n' identical rotors.

$C_{S T}=$ cost of single rotor wind turbine.

$C_{s i} \& C_{m i}$ are the costs of $\mathrm{i}^{\text {th }}$ component of respective wind turbines.

$C_{t s,} C_{f s,} \mathrm{C}_{g s}$ and are the costs of tower, foundation, gear box of single rotor wind turbine.

$C_{s(\circ \mathrm{sm})}$ is operational and maintenance cost of single rotor wind turbine.

$\mathrm{k}_{\mathrm{n}}=\frac{1}{\sqrt{\mathrm{n}}}$

$\mathrm{k}_{0 \& m}$ varies from 1 to 1.15 , the values are dependent upon the facts that whether rotors maintenance is simultaneous or altogether at different intervals. If required this can be used to find out the cost of generation. Presently it has been taken as 1.

\section{SIMULATION RESULTS AND DISCUSSION}

Table 1 shows the specifications of wind turbine NORDEX- N117-3000 kW and LEITWIND- LTW77-1000 kW selected to compare the simulated results in case of single-rotor and multi-rotor wind turbines respectively. Power output curves as shown in figure 4 are considered to find out the annual energy yield. Rated power of each turbine is considered as its base power. 
Table 1. Specifications of turbines

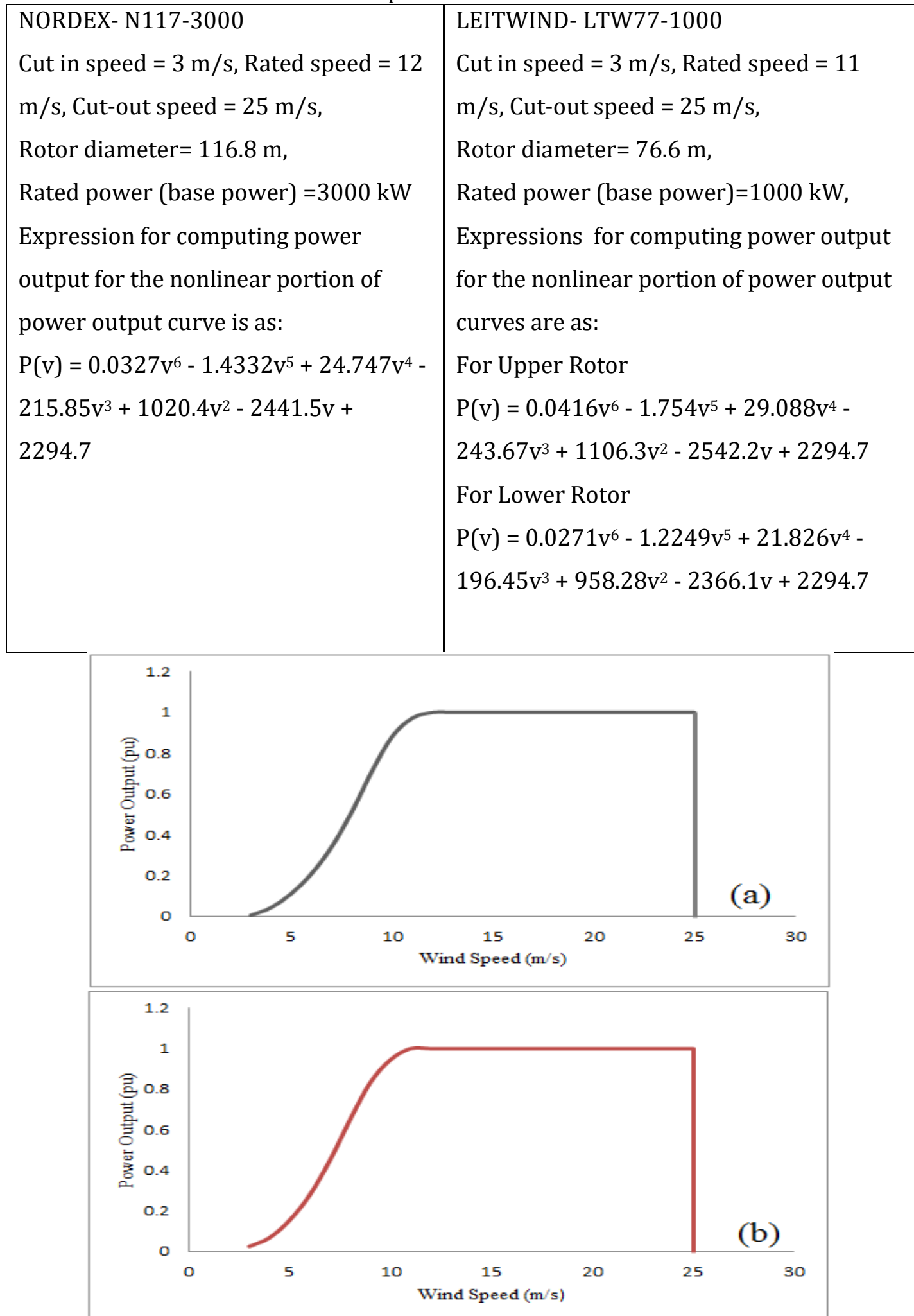

Figure 4. Power output curve (a) NORDEX-N117 turbine, (b) LEITWIND-LTW77 turbine 


\subsection{Annual Energy Yield}

In order to compute the annual energy yield of turbines, Weibull distributions of wind is shown in figure 5. Mean wind speed varies from $5 \mathrm{~m} / \mathrm{s}$ to $12 \mathrm{~m} / \mathrm{s}$, with shape factor $(\mathrm{k})$ as $1,2 \& 3$.
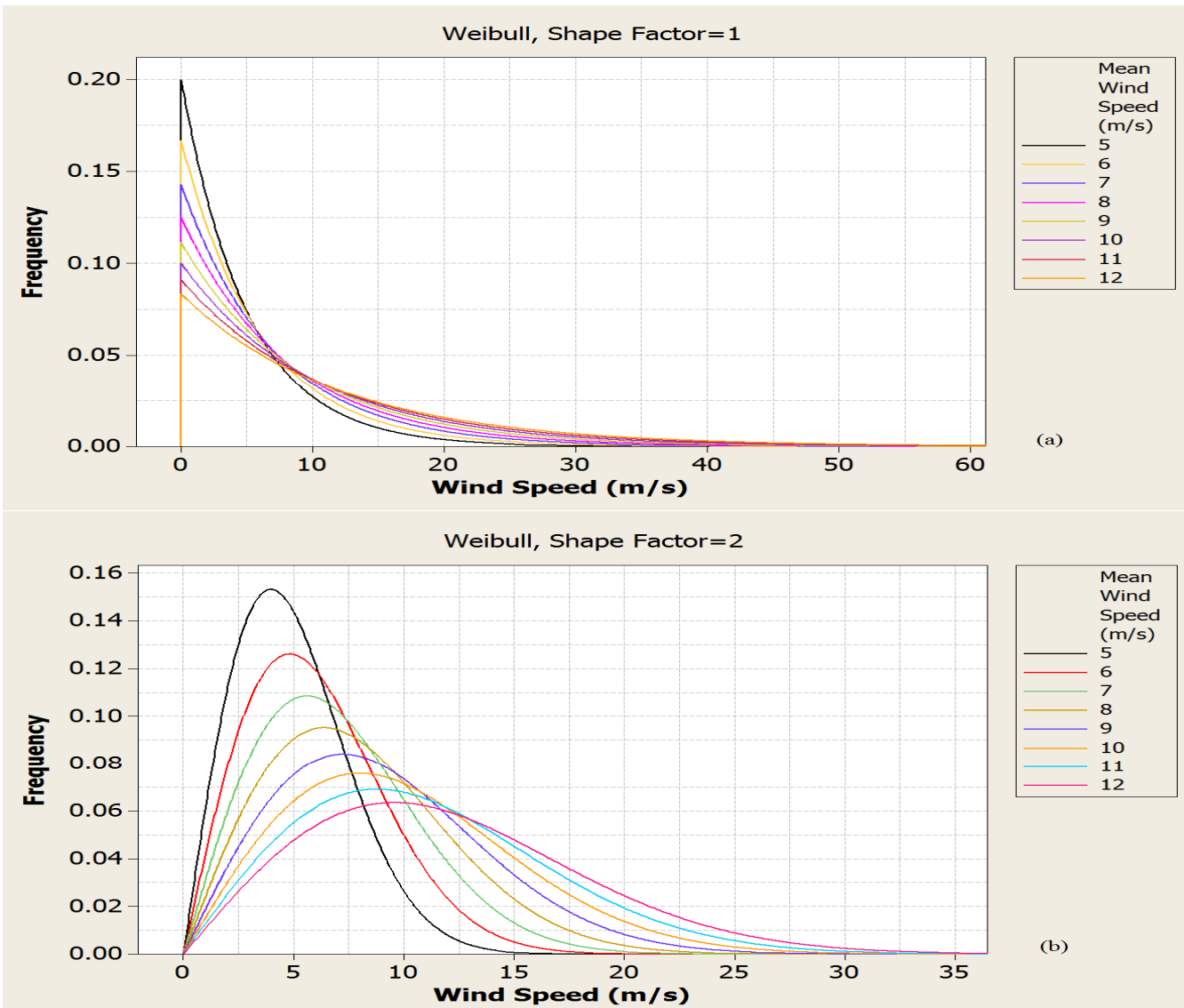

Weibull, Shape Factor $=3$
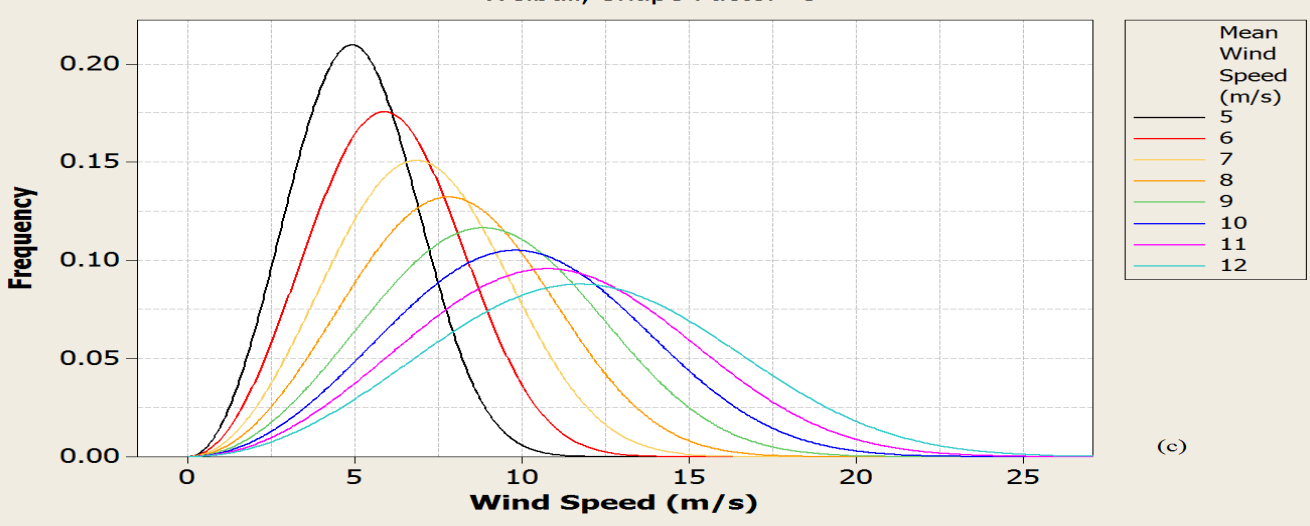

Figure 5. Weibull distribution (a) $k=1$, (b) $k=2$, (c) $k=3$.

Equations (3), (6) and (7) are used to compute the annual energy output for any Weibull distribution. For simulation purpose NORDEX-117-3000 kW is taken as a single rotor wind turbine. The group of three identical 
LEITWIND-LTW77-1000 kW turbines is considered as an equivalent multirotor wind turbine. Rated capacity of this combination $(3 \times 1000 \mathrm{~kW})$ is same as that of single rotor wind turbine.

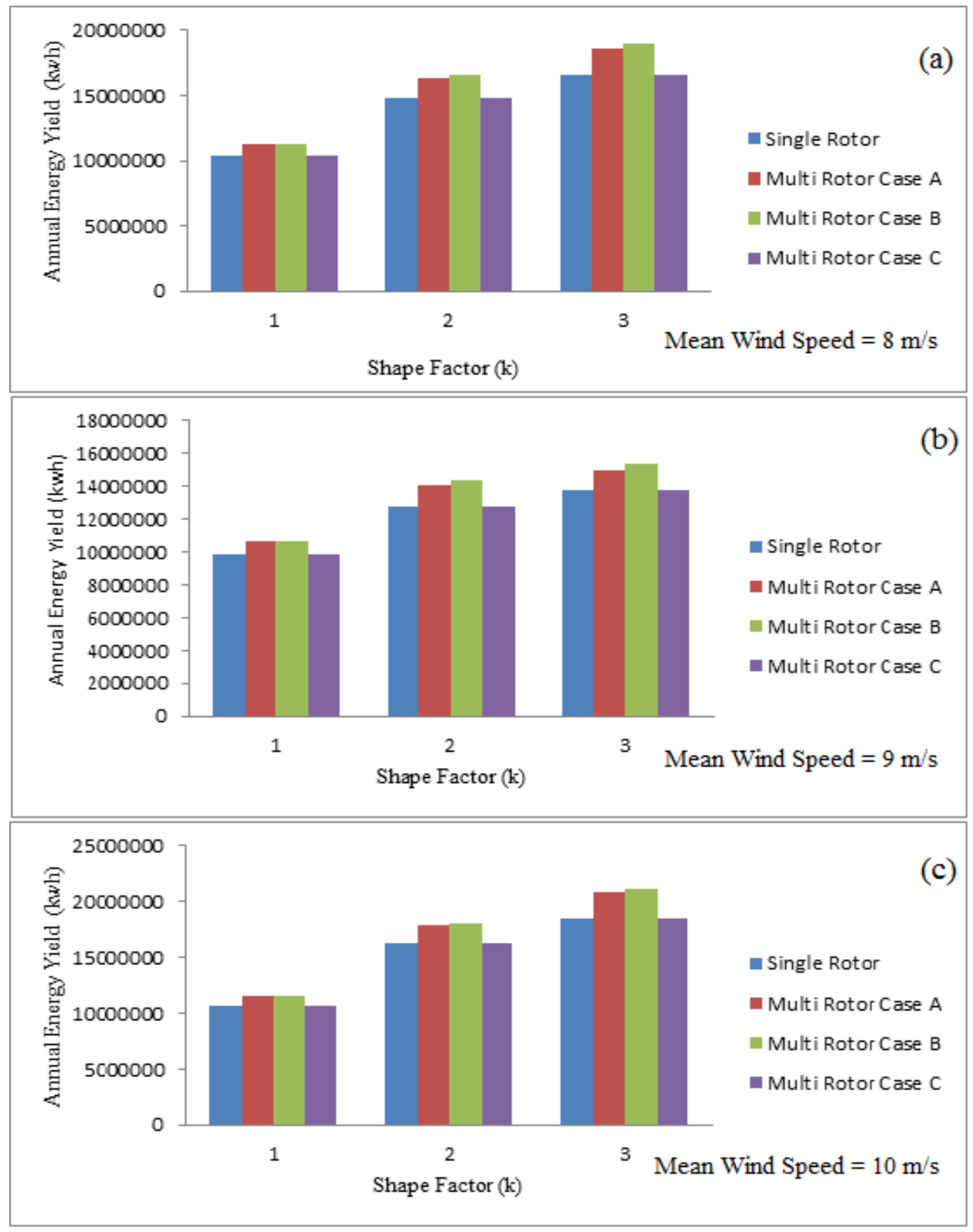

Figure 6. Annual energy yield of wind turbines at different mean wind speeds

Figures 6 shows the comparison of annual energy yield by the two types of turbines when operated under identical wind conditions i.e. same mean wind speeds \& shape factor. For comparison purpose (figure 6) mean wind speeds as $8 \mathrm{~m} / \mathrm{s}, 9 \mathrm{~m} / \mathrm{s}$ and $10 \mathrm{~m} / \mathrm{s}$ have been considered. As far as mean wind 
speeds are concerned, these should be close to rated one. Such selection gives the effective utilization of wind turbines. There are many windy sites (figure 7) where mean wind speeds lies in between 8 to $10 \mathrm{~m} / \mathrm{s}$.

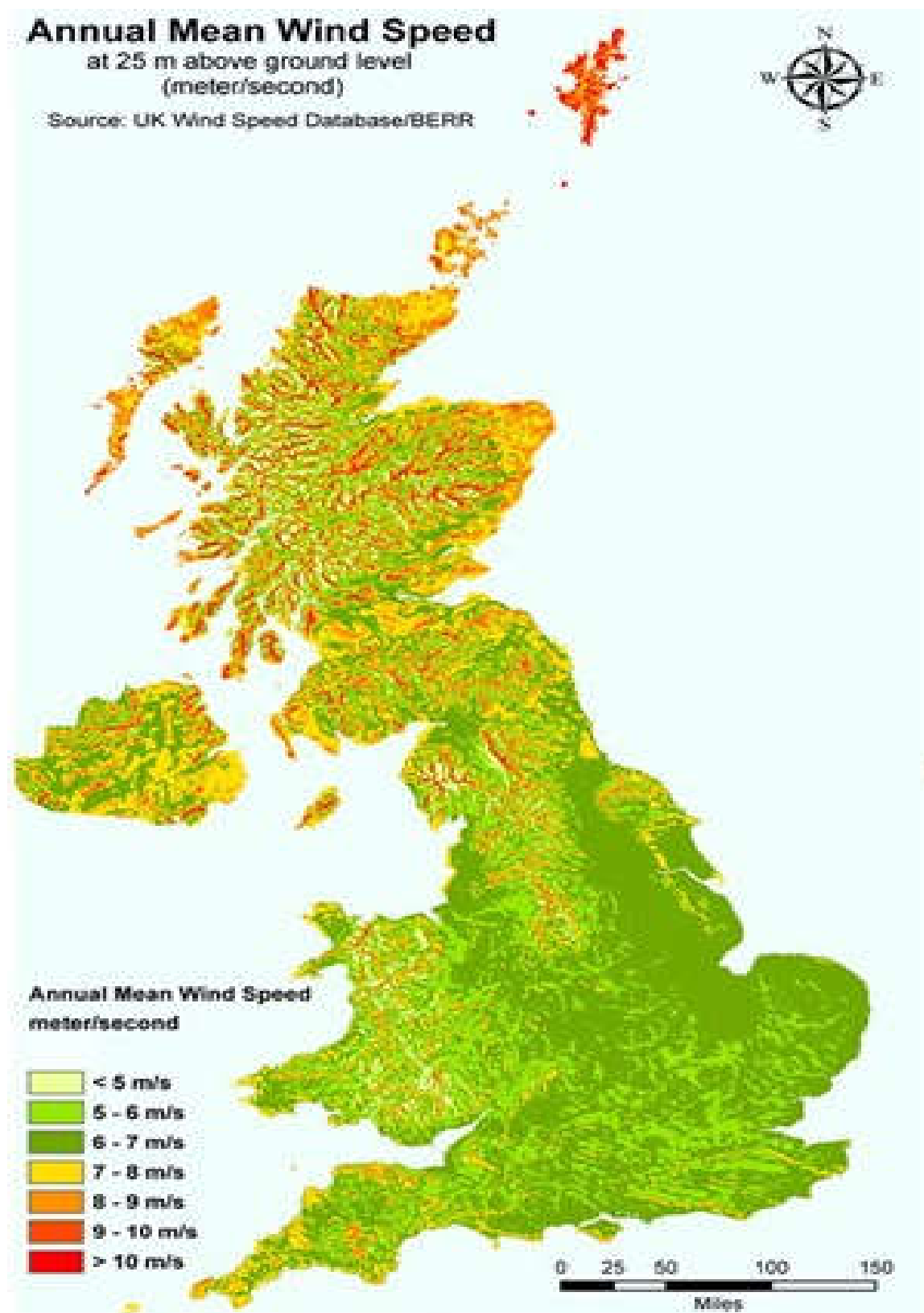

Figure 7. UK wind sites with annual mean wind speed $\geq 8 \mathrm{~m} / \mathrm{s}$ [source: UK Wind Speed Database/BERR]

As observed, energy output of multi-rotor wind turbine in case-A and case- $B$ is always more than that of single rotor wind turbine. It comes out to be same as per case- $C$ configuration. However excessive energy produced by the multi-rotor turbine varies with its configuration (i.e case-A and B). Percentage 'Excessive Annual Energy Production [EAEP]' as obtained is 
shown in Table 2. As per literature [27-30], value of $\mathrm{k}$ is generally greater than 1.6. Therefore, simulation results [table 2] for EAEP have been considered accordingly (i.e. for $\mathrm{k}=2$ and 3 ).

$$
\% \text { ageEAEP }=\frac{E_{M}-E}{E} \times 100
$$

Where;

$E_{M}=$ Annual energy yield of multirotor turbine for respective case i.e. case-A, B or C

$E=$ Annual energy yield of single rotor wind turbine.

Table 2. Excessive annual energy production (EAEP)

\begin{tabular}{|c|c|c|c|c|}
\hline \multirow{2}{*}{$\begin{array}{c}\text { Mean } \\
\text { Wind } \\
\begin{array}{c}\text { Speed } \\
\text { (m/s) }\end{array}\end{array}$} & \multicolumn{2}{|c|}{$\begin{array}{c}\text { \%age Excessive Energy } \\
\text { Produced with k=2 }\end{array}$} & \multicolumn{2}{c|}{$\begin{array}{c}\text { \%age Excessive Energy } \\
\text { Produced with k=3 }\end{array}$} \\
\cline { 2 - 5 } & Case A & Case B & Case A & Case B \\
\hline 7 & 8.46 & 11.47 & 2.14 & 6.10 \\
\hline 8 & 9.62 & 11.96 & 8.40 & 11.29 \\
\hline 9 & 10.12 & 11.88 & 12.31 & 14.40 \\
\hline 10 & 9.74 & 11.02 & 12.83 & 14.41 \\
\hline 11 & 9.18 & 9.99 & 12.06 & 13.26 \\
\hline 12 & 8.98 & 9.33 & 11.46 & 12.33 \\
\hline
\end{tabular}

Simulation data gives the following observations.

- The annual energy production depends upon the shape of Weibull distribution curve. This shape varies with the shape factor $\mathrm{k}$ (figure 5). For any value of $\mathrm{k}$ ( 2 or 3 ) if mean wind speed increases, the peak point moves downwards and also horizontally to right side. Simultaneously it results in to the wide operation of turbine from cut-in to cut-out speeds (as visible from the base of curves (figure 5). It results in to more energy yield, due to the movement of peak towards rated wind speed and wide operation of wind turbine beyond cut-in speeds. But after a specific value of mean wind speed energy yield again starts decreasing. Now this reduction is due to the reduction of peak point continuously but effectively a very small change in the operating speeds on the base of curve. There is a unique combination of the two parameters (i.e ' $\mathrm{f}$ ' on $\mathrm{y}$ axis and ' $\mathrm{v}$ ' on $\mathrm{x}$ axis) which will result in to the maximum excessive energy yield. This appears at mean wind speeds of $8 \mathrm{~m} / \mathrm{s}$ and $10 \mathrm{~m} / \mathrm{s}$ respectively for the values of $\mathrm{k}$ as 2 and 3 . At 
large value of mean wind speeds excessive energy yield in case of $\mathrm{k}=3$ comes to be more as compared those with $\mathrm{k}=2$. It is due to the corresponding higher peak value and its occurrence about rated speed.

- Multi-rotor configurations (case-A \& case-B) yield more energy in contrast to their counterpart i.e. single rotor wind turbine.

- Excessive annual energy production by multi-rotor configuration as per case-B is always greater than that for case-A, therefore recommended for replacement.

- Difference of EAEP due to two multi-rotor configurations is large for lower values of mean wind speed. This difference decreases with an increase in the mean wind speed of rotor.

From above it is summarized that selection of configuration as per case-B is always economical in terms of annual energy production. Simulation results as presented in the Table 2 , shows the effect of geometrical locations of multi-rotors on its annual energy production (for given value of mean wind speed).

Apart from above, performance may be affected due to the following:

- Reduction in annual energy yield due to shut down of plant for scheduled and unscheduled maintenance. These can be dealt in the following ways:

i) Scheduled maintenance time is taken as 3\% of annual period at different times but simultaneously for both types of turbines \& for all rotors. For such cases \%age EAEP remains unaffected. Generally scheduled maintenance works are carried out during no wind zones and hence does not affect energy yield. But these are to be planned very carefully.

ii) Unscheduled maintenance works are unpredictable and hence cannot be planned. One of the possibilities is to repair the three rotors of a multirotor wind turbine at different periods with $3 \%$ downtime. This type of maintenance if permitted will cause more reduction of annual energy yield due to multi rotor configuration. 
However effects of scheduled and unscheduled maintenance on annual energy yield of turbines can be included in equation (16) as:

$$
\% \text { age } E A E P=\frac{E E_{M}-E E}{E E} \times 100
$$

Where,

$E E_{M}=$ Effective annual energy yield of multirotor wind turbine $=E_{M}-\left[\mathrm{LOE}_{\mathrm{M}}\right]$

LOEM =Loss of energy of multi rotor wind turbine due to plant shut down $=\sum_{i=1}^{i=n}\left(P_{M i} f_{i} t_{i}\right)$

$P_{M i}=$ Power output of multirotor wind turbine for $\mathrm{i}^{\text {th }}$ interval

$f_{i}=$ wind frequency for $\mathrm{i}^{\text {th }}$ interval

$t_{i}=$ time duration for $\mathrm{i}^{\text {th }}$ interval

$E E=$ Annual energy yield of single rotor wind turbine

$=E-[\mathrm{LOE}]$

LOE =Loss of energy of single rotor wind turbine due to plant shut down $=\sum_{i=1}^{i=n}\left(P_{i} f_{i} t_{i}\right)$

$P_{i}=$ Power output of single rotor wind turbine for $\mathrm{i}^{\text {th }}$ interval

- Multirotor wind turbine will result in to an increase of noise level (Appendix B). It increases from $102 \mathrm{~dB}$ to $111.5 \mathrm{~dB}$, but still within permissible limits.

- Turbines (if not disconnected from grid) will absorb the energy during the periods when wind speed falls below the cut-in speed. Such energy consumption depends upon the power consumed by the mechanical and electrical parts of the wind turbine i.e. upon the weight of rotor, efficiency of mechanical transmission system (gear box) and efficiency of electrical generator. A comparison for such energy absorption has been shown in Appendix-C. As observed this is less in case of multirotor wind turbine with configuration as recommended i.e. Case-B.

\subsection{Economic Analysis}

Cost model equations as discussed (section 4) are used for economic analysis of wind turbines. Table 3 shows the cost comparison of conventional single rotor wind turbine and multi-rotor wind turbine. 
Table 3. Breakdown of wind turbine components cost

\begin{tabular}{|c|c|c|c|}
\hline \multirow{2}{*}{$\begin{array}{l}{[24-} \\
26]\end{array}$} & \multicolumn{2}{|c|}{ Project Cost of $3000 \mathrm{~kW}$ Wind Project $\longrightarrow$} & 4433000 USD \\
\hline & Cost of Single Rotor Wind Turbine of 3000 & ind Turbine of 3000 & 3058770 USD \\
\hline $\begin{array}{l}\text { Sr } \\
\text { No }\end{array}$ & $\begin{array}{l}\text { Wind turbine } \\
\text { component }\end{array}$ & $\begin{array}{c}\text { Component costs (\$) } \\
\text { of Single-rotor wind } \\
\text { turbine }\end{array}$ & $\begin{array}{c}\text { Component costs }(\$) \\
\text { of Multi-rotors wind } \\
\text { turbine }\end{array}$ \\
\hline 1 & Rotor Blades & 627604 & 581740 \\
\hline 2 & Rotor Hub & 102214 & 141336 \\
\hline 3 & Rotor Bearing & 72780 & 49308 \\
\hline 4 & Pitch System & 163477 & 158611 \\
\hline 5 & Gearbox( with kg=1) & 366272 & 366272 \\
\hline 6 & Tower & 726125 & 508287 \\
\hline 7 & Foundation & 709280 & 409502 \\
\hline 8 & Other components & 291018 & 291018 \\
\hline 9 & $\begin{array}{l}\text { Support Structure } \\
\text { (Spars + Cables) }\end{array}$ & -- & $46872^{*}$ \\
\hline & Total Cost & 3058770 & 2552946 \\
\hline
\end{tabular}

*prices as per USA market

Figure 8 shows the \%age cost saving of multi rotor wind turbine in terms of factor kg. It is observed the cost saving may be enhanced with careful design of gearbox. 


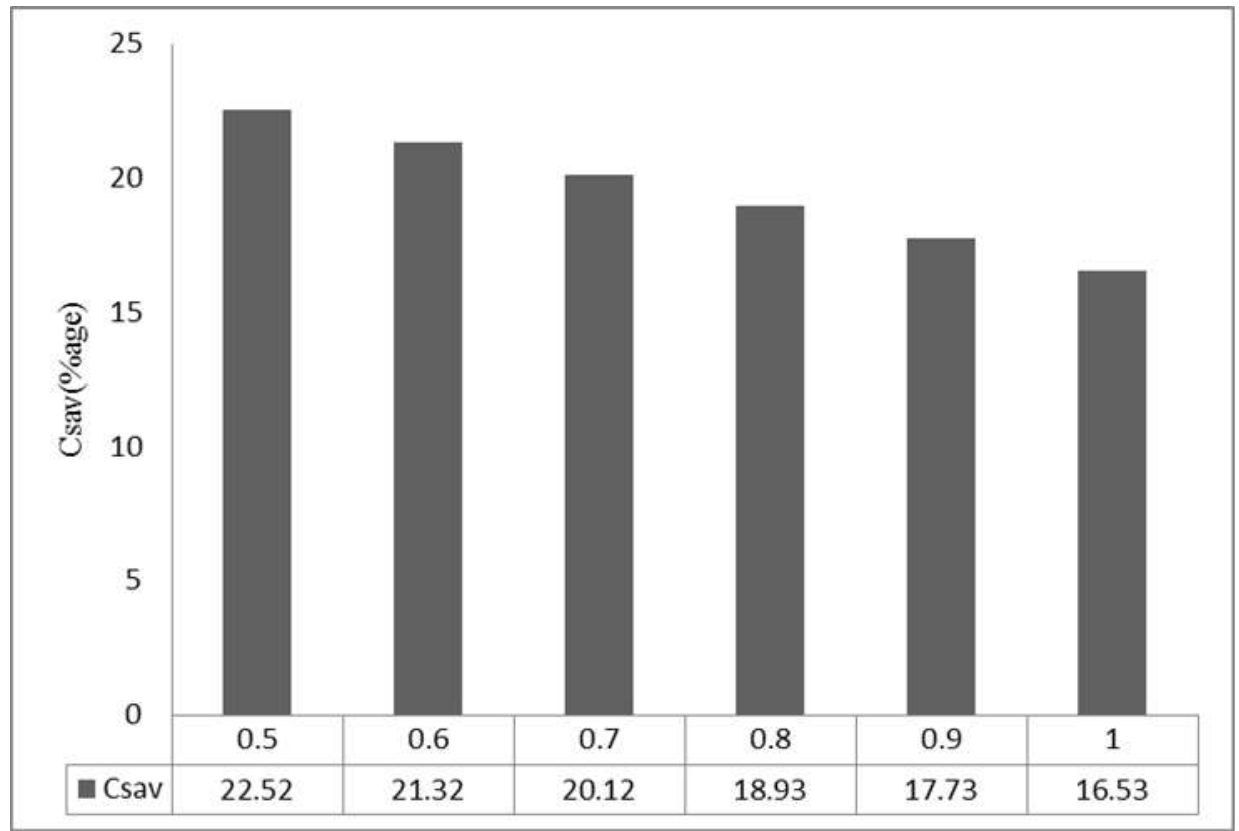

Figure 8. Percentage saving for three rotor wind turbine with variation of constant

\section{CONCLUSION}

$\mathrm{kg}_{\mathrm{g}}$

Focus of present study is to investigate the economics \& performance of equivalent multi-rotor wind turbines in place of single rotor configuration. Power and energy models as developed are used to estimate the annual energy yield of multi-rotor wind turbine. Cost model as proposed may be used to compare the economics of multi-rotor wind turbines. As observed equivalent multi-circuit wind turbine with specific configurations (case-A \& case-B) generates more energy in contrast to single-rotor construction. This excessive energy production also varies with the geometrical location of rotors. Case-B configuration is found to be more profitable in terms of energy yield. On other hand installation cost of equivalent of multi-rotor wind turbine appears to be cheaper than that of single rotor wind turbine. This cost of multi-rotor wind turbine comes out to be $83.47 \%$ of single rotor turbine.

\section{REFERENCES}

[1] Mathew S, Wind Energy Fundamentals, Resource Analysis and Economics, Springer (Netherland), 2006.

[2] Ackermann T, Wind Power in Power Systems, Wiley (United Kingdom), 2005.

[3] Zobaa FA, Bansal CR, Handbook of Renewable Energy Technology, World Scientific (Singapore), 2011.

[4] European Wind Energy Association, Upwind Design Limits And Solution for Very Large Wind Turbines: A 20 MW Turbine Is Feasible, 2011. 
[5] Hirahara H, Hossain ZM, Kawahashi M, Nonomura Y, Testing Basic Performance of a Very Small Wind Turbine Designed for MultiPurposes, Elsevier Renewable Energy, Vol. 30, pp. 1279-1297, 2005.

[6] Rosa DVA, Fundamentals of Renewable Energy Processes, Elsevier (United States of America), pp. 599, 2005.

[7] European Wind Energy Association, Wind Energy the Facts Part 1 Technology, 2005.

[8] Jamieson P, Branney M, Multi-Rotors: A Solution to 20 Mw and Beyond, Elsevier Energy Procedia Deepwind, Vol. 24, pp. 52-59, 2012. DOI: 10.1016/j.egypro.2012.06.086.

[9] Jamieson P, Innovation in Wind Turbine Design, Wiley (United Kingdom), Ed. 2, pp. 229-238, 2011.

[10] Dick E, Aerodynamic Optimisation of a Multirotor Wind Energy System with a Large Diameter Tower, Wind Engineering, Vol. 11, No. 4, pp. 207-224, 1978.

[11] Kotab AM, Solimon AH, Performance of a Staggered Multi Rotor Horizontal Axis Wind Turbine System, Elsevier Journal of Wind Engineering and Industrial Aerodynamics, Vol. 45, pp. 139-152, 1993.

[12] No ST, Kim HJ, Moon HJ, Kim JS, Modeling, Control and Simulation of Dual Rotor Wind Turbine Generator System, Elsevier Renewable Energy, Vol. 34, pp. 2124-2132, 2009. DOI: 10.1016/j.renene.2009.01.019.

[13] Yap TH, Ong CZ, Chong TW, Kong KK, Khoo YS, Ismail Z, Rahman AGA, Design Optimisation of Shroud-Augmented Dual Rotor Exhaust Air Energy Recovery Wind Turbine Generator Using Hybrid NonDestructive Evaluation Approach, Elsevier Energy Procedia $6^{\text {th }}$ International Conference on Applied Energy (ICAE), Vol. 61, pp. 12661269, 2014. DOI:10.1016/j.egypro.2014.11.1077.

[14] Habash YWR, Groza V, Guillemette P, Performance Optimization of a Dual Rotor Wind Turbine System, IEEE Electrical Power \& Energy Conference 2010.

[15] Farahani ME, Hosseinzadeh N, Ektesabi MM, Comparison of Dynamic Responses of Dual and Single Rotor Wind Turbines under Transient Conditions, IEEE ICSET 2010.

[16] Farahani ME, Hosseinzadeh N, Ektesabi M, Comparison of Fault-RideThrough Capability of Dual and Single Rotor Wind Turbines, Elsevier Renewable Energy, Vol. 48, pp. 473-481, 2012. DOI: 10.1016/j.renene.2012.06.010.

[17] Huang Q, Shi Y, Wang Y, Lu L, Cui Y, Multi Turbine Wind Solar Hybrid System, Elsevier Renewable Energy, Vol. 76, pp. 401-407, 2015.

[18] Jamieson P, Branney M, Structural Considerations of a 20 Mw Multi Rotor Wind Energy System, Journal of Physics: The Science of Making Torque from Wind, Vol. 555, pp. 1-8, 2015. DOI: 10.1088/17426596/555/1/01/2013. 
[19] Smulders PT, Orbons S, Moes C, Aerodynamic Interaction Between Two Wind Rotors Set Next To Each Other in One Plane, European Wind Energy Conference, Hamburg 1984.

[20] Ransom D, Moore JJ, Heronemus-Pate M, Performance of Wind Turbine in a Closely Spaced Array, Renewable Energy World Magazine: North America May/June 2010, Vol. 2, No. 3, pp. 32-36, 2010.

[21] Samorani M, The Wind Farm Layout Optimization Problem, Handbook of Wind Power System, Energy System, Springer (Berlin Heidelberg), pp. 21-38, 2013. DOI: 10.1007/978-3-642-41080-2_2.

[22] Fingersh L, Hand M, Laxson A, Wind Turbine Design Cost and Scaling Model, National Renewable Energy Laboratory, 2006.

[23] Blanco IM, The Economics of Wind Energy, Elsevier Renewable and Sustainable Energy Reviews, Vol. 13, pp. 1372-1382, 2009.

[24] www.renewablesfirst.co.uk

[25] www.conserve-energy-future.com

[26] www.local.gov.uk

[27] Basumatary H, Sreevalsan E, Sasi KK, Weibull Parameters Estimation - a Comparison of Different Methods, Wind Engineering, Vol. 29 (3), pp. 309-316, 2005.

[28] Chang TP, Performance Comparison of Six Numerical Methods in Estimating Weibull Parameters for Wind Energy Application, Elsevier Applied Energy, Vol. 88, pp. 272-282, 2011.

[29] Carrillo C, Cidras J, Dorado ED, Montano AFO, An Approach To Determine The Weibull Parameters for Wind Energy Analysis: The Case of Galicia (Spain), Energies, Vol. 7, pp. 2676-2700, 2014. DOI: 10.3390/en7042676.

[30] Azad AK, Rasul MG, Alam MM, Uddin SMA, Mondal SK, Analysis of Wind Energy Conversion System Using Weibull Distribution, Elsevier Procedia Engineering 10 $10^{\text {th }}$ International Conference on Mechanical Engineering (ICME-2013), Vol. 90, pp. 725-732, 2014. DOI: 10.1016/j.proeng.2014.11.803.

[31] Rogers AL, Manwell JF, Wright S, Wind Turbine Acoustic Noise, Renewable Energy Research Laboratory, June 2002 Amended January 2006. 


\section{Appendix A}

Weight and Shapes of Towers

Weight of tower is computed as:

$$
W_{t}=\Pi D t H \rho_{m}
$$

Where

$\mathrm{D}=$ diameter of tower,

$\mathrm{t}=$ thickness of tower sheet,

$\mathrm{H}=$ height of tower,

$\rho_{m}=$ density of tower material

The dimensions ( $D$ and $t$ ) of the tower should be sufficient to prevent local shell building. This requires fulfilment of following condition.

Axial stress $\left(\sigma_{\mathrm{a}}\right)+$ Bending stress $\left(\sigma_{\mathrm{b}}\right) \leq$ Critical building stress $\left(\sigma_{\mathrm{cr}}\right)$

Axial stress vertically acting on the tower can be expressed as:

$$
\sigma_{a}=\frac{M_{n r} g}{\Pi D t}
$$

Where,

$\mathrm{M}_{\mathrm{nr}}=$ Mass of rotor and nacelle,

$\mathrm{g}=$ Gravitational acceleration

Bending stress horizontally working on the tower can be expressed as:

$$
\begin{gathered}
\sigma_{b}=\frac{4 M_{b}}{\Pi D^{2} t} \\
\mathrm{M}_{\mathrm{b}}=\text { bending moment }=\frac{P_{w} H}{2} \\
P_{w}(\text { Wind Load })=\mathrm{Wp} \mathrm{C}_{\mathrm{d}} \mathrm{C}_{\mathrm{e}} \mathrm{C}_{\mathrm{s}} \mathrm{H} \mathrm{D}
\end{gathered}
$$

$\mathrm{Wp}=$ Wind pressure including gust effect,

$\mathrm{C}_{\mathrm{d}}=$ Drag coefficient,

$\mathrm{C}_{\mathrm{e}}=$ Exposure coefficient,

$\mathrm{C}_{\mathrm{s}}=$ Shape factor

Equations (A4) \& (A5) give the following.

$$
\sigma_{b}=\frac{4}{\Pi D^{2} t}\left[\frac{W_{p} C_{d} C_{e} C_{s} H^{2} D}{2}\right]=\frac{2 W_{p} C_{d} C_{e} C_{s} H^{2}}{\Pi D t}
$$


Equations (A2), (A3) \& (A6) give the following.

$$
\frac{M_{n r} g}{\Pi D t}+\frac{2 W_{p} C_{d} C_{e} C_{s} H^{2}}{\Pi D t} \leq \sigma_{c r}
$$

Above equation is used to decide the tower dimensions i.e. D \& t. For nrotor turbine, 'Mnr' becomes $\frac{1}{\sqrt{n}}(\mathrm{Mnr}$ for single rotor turbine). This reduction can be compensated for ' $\sigma_{a}$ ' by changing the tower dimensions (i.e. D \& t) accordingly. Hence there is a scope to reduce the product ' $\mathrm{Dt}$ ' by $\frac{1}{\sqrt{n}}$ times.

For a three rotor configuration it comes out to be 0.57 times the dimensions in case of single rotor. However $\sigma_{b}$ becomes 1.7543 times in case the product ' $D t$ ' decreases by 0.57 . On the other hand, $\sigma_{\mathrm{b}}$ can also be controlled by changing the shape of tower i.e. with the help of $\mathrm{C}_{\mathrm{s}}$. Therefore instead of $57 \%$, the product ' $\mathrm{Dt}$ ' can be reduced safely by $70 \%$. This change will affect the $\sigma_{\mathrm{a}}, \sigma_{\mathrm{b}}$ and weight of turbine as:

$\checkmark \sigma_{\text {a becomes }} 0.814$ times its value for single rotor turbine.

$\checkmark \sigma_{\mathrm{b}}$ remains same as its value for single rotor turbine.

$\checkmark$ Weight of tower in case of multirotor turbine $=0.7$ times the weight of tower in case of single rotor turbine. 


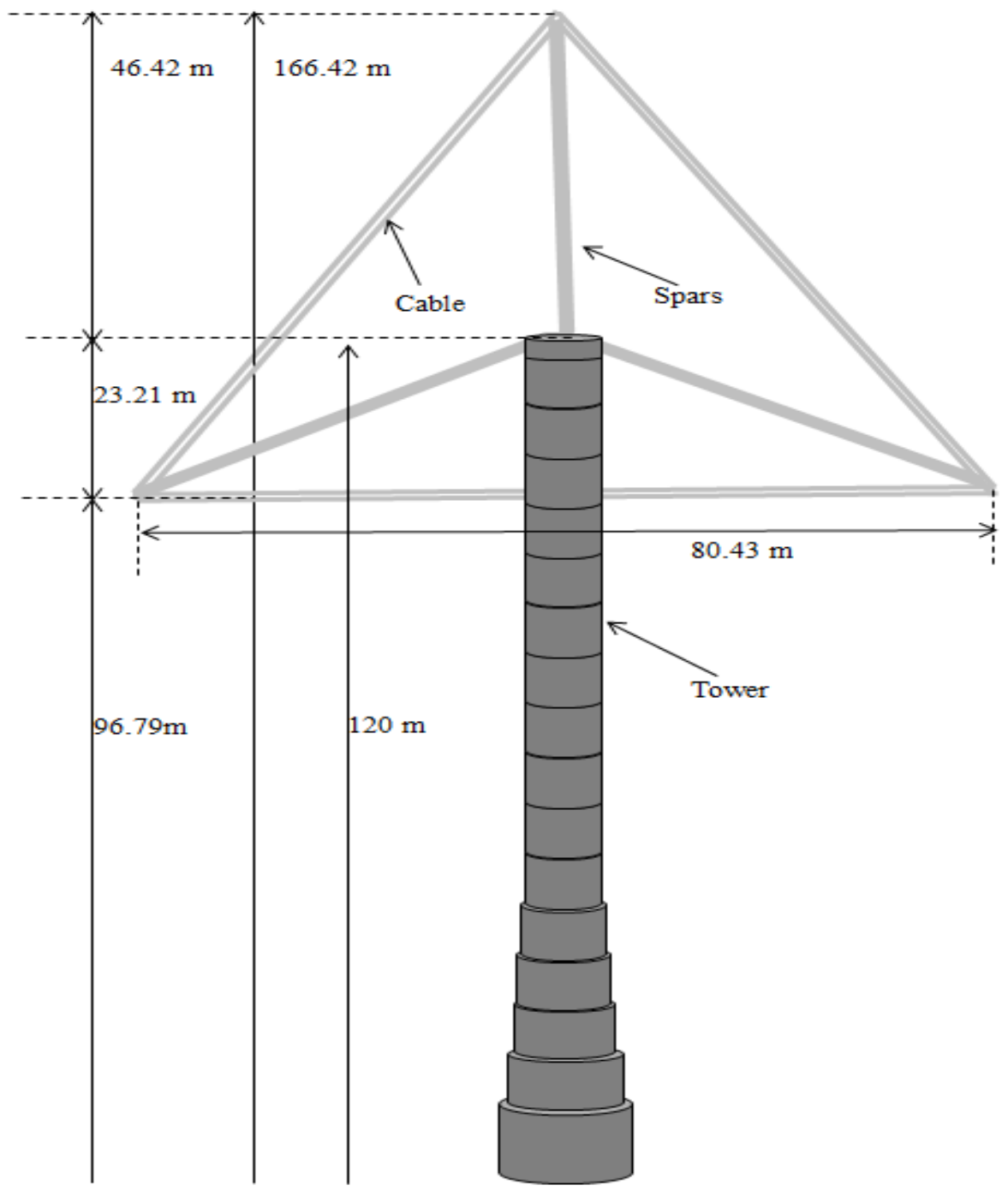

Figure A1 (a). Shapes of towers for a multirotor wind turbine for Case-A 


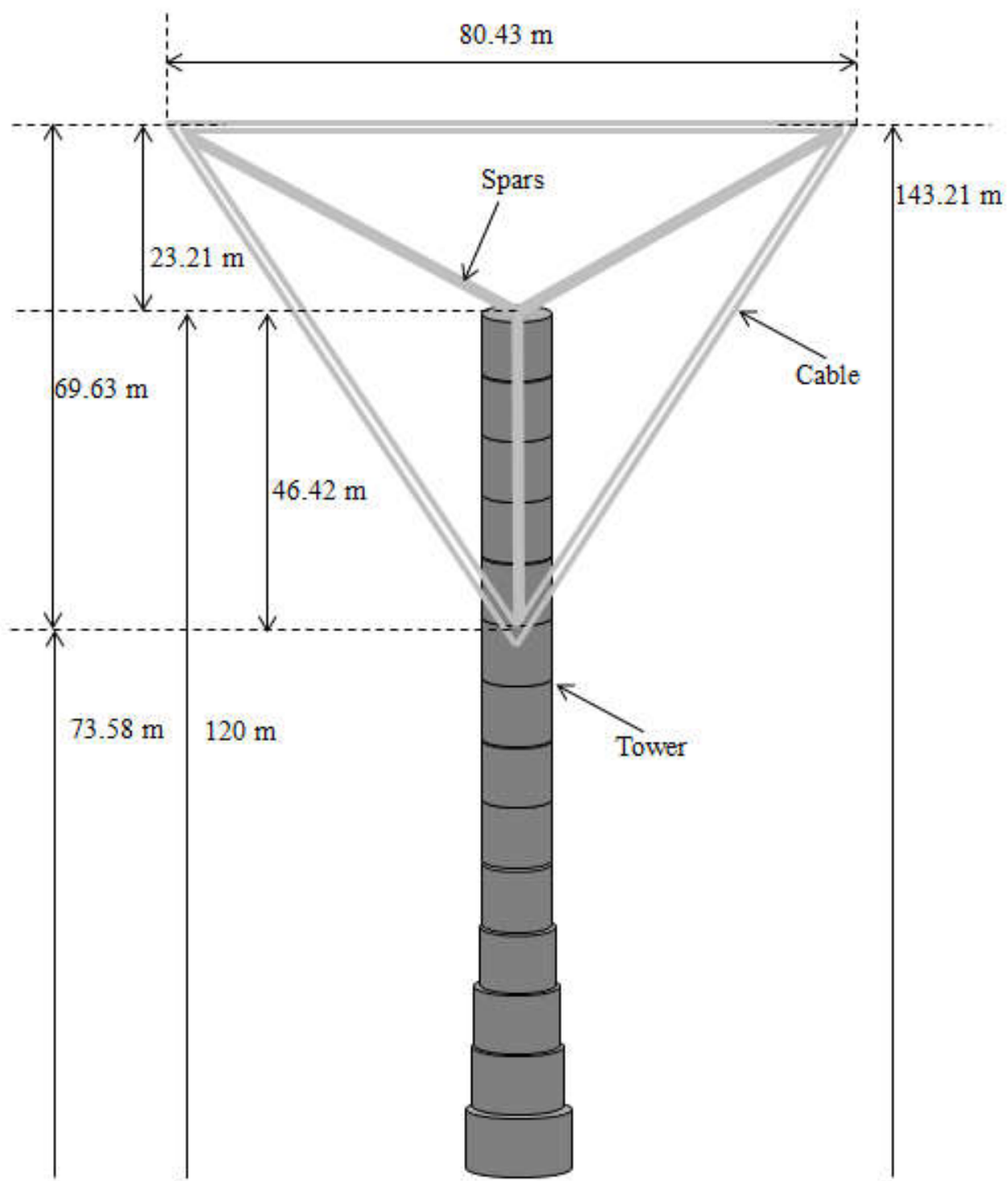

Figure A1 (b). Shapes of towers for a multirotor wind turbine for Case-B 


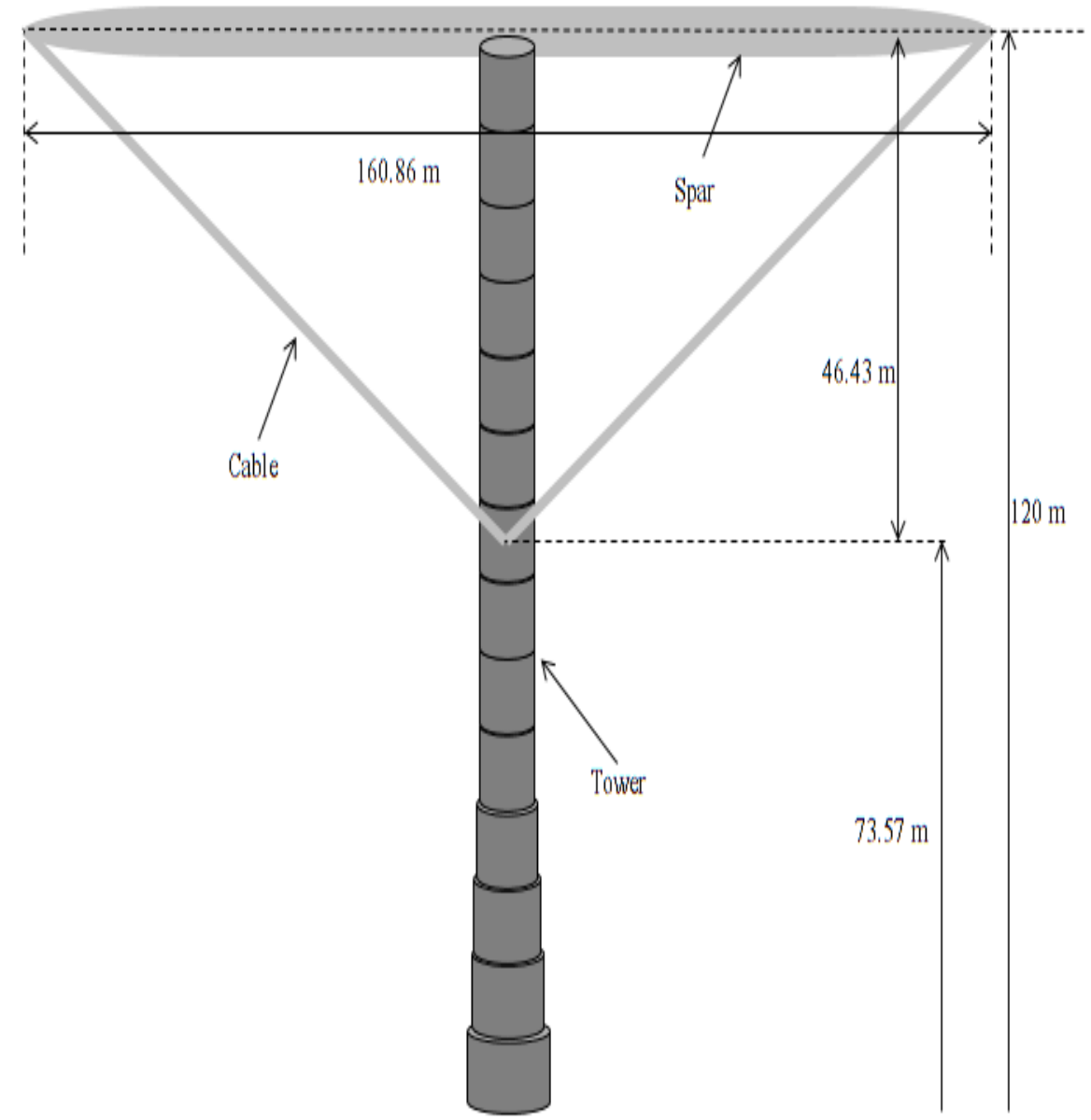

Figure A1 (c). Shapes of towers for a multirotor wind turbine for Case-C

As shown in figure A1, an additional weight of spars and cables changes the weight of multi-rotor tower as 0.76 times the weight of tower in case of single rotor turbine. Still with this additional weight, axial and bending stresses as defined by equations (A3) \& (A6) remains unaffected.

As discussed in section 5.1, Case-C is not recommendable. Projected area for other cases increases by $30 \%$ but symmetry is maintained. However such changes can be compromised with low cost and economical operation (section 5.2). 


\section{Appendix B}

\section{Noise Level of turbines}

Peak noise level of $3000 \mathrm{~kW}$ turbine $=106 \mathrm{~dB}$

Peak noise level of $1000 \mathrm{~kW}$ turbine $=102 \mathrm{~dB}=2.5178 \mathrm{~Pa}$

Peak noise level of multirotor wind turbine [31] = $20 \log \left[\left(3^{*} 2.5178\right) /\right.$ $\left.\left(2^{*} 10^{\wedge}-5\right)\right]$

$$
=111.5 \mathrm{~dB}
$$

\section{Appendix C}

Table C1. Annual energy consumption of wind turbines

\begin{tabular}{|c|c|c|c|c|c|c|}
\hline \multirow{2}{*}{$\begin{array}{c}\text { Mean } \\
\text { wind } \\
\text { speed } \\
\text { (m/s) }\end{array}$} & \multicolumn{3}{|c|}{ Energy Consumption (kWh) with } & \multicolumn{3}{|c|}{$\begin{array}{c}\text { Energy Consumption (kWh) } \\
\text { with k=3 }\end{array}$} \\
\cline { 2 - 7 } & $\begin{array}{c}\text { Single } \\
\text { Rotor } \\
\text { Wind } \\
\text { Turbine }\end{array}$ & Case A & Case B & $\begin{array}{c}\text { Single } \\
\text { Rotor } \\
\text { Wind } \\
\text { Turbine }\end{array}$ & Case A & Case B \\
\hline 7 & 135608.37 & 136191.14 & 133927.41 & 84472.53 & 85556.60 & 81949.74 \\
\hline 8 & 108001.14 & 108523.41 & 106555.85 & 58151.85 & 58929.06 & 56375.85 \\
\hline 9 & 86178.47 & 86629.75 & 84962.05 & 40414.64 & 40967.54 & 39161.12 \\
\hline 10 & 71351.14 & 71743.43 & 70310.03 & 29923.19 & 30339.76 & 28988.48 \\
\hline 11 & 59965.98 & 60307.44 & 59069.73 & 22749.12 & 23068.58 & 22034.21 \\
\hline 12 & 51056.81 & 51355.36 & 50280.04 & 17685.39 & 17935.39 & 17127.45 \\
\hline
\end{tabular}

